\title{
The annual cycle of African climate and its variability
}

\author{
MR Jury* and EJ Mpeta\# \\ Environmental Science Dept, University of Zululand, KwaDlangezwa, 3886, South Africa
}

\begin{abstract}
A statistical analysis of African rainfall and temperature, and surface wind components and sea level pressure over the tropical Atlantic and Indian Oceans is done in the period 1965 to 1995. The annual cycle is found to be the dominant mode, exhibiting a subtropical north - south dipole with a cycle period of 12 months. The second mode is equatorial with 6-month oscillations prevalent. Annual cycle variance is of the order of $40 \%$, compared with $\sim 10 \%$ for the interannual residual. The north-south alternation of winds over the adjacent oceans accounts for $92 \%$ of north-south rainfall oscillations over the African continent. The annual cycle varies coherently over periods of 3 to 8 years. Years of high (low) annual cycle correspond with La Nina (El Nino) and increased (decreased) inter-annual fluctuations of the African climate. A composite analysis shows that the South Atlantic Hadley cell and standing waves in the subtropical jet may connect annual and interannual signals.
\end{abstract}

Keywords: annual cycle, African monsoon, climate diagnostics

\section{Introduction}

The annual cycle of the earth's climate is forced by solar insolation and corresponding surface fluxes that vary from summer to winter. There is a surplus of heat energy in the tropical zone that is exported pole-ward in both the ocean and atmosphere. These features may conspire to produce monsoon circulations, wherein the atmospheric Hadley cells are amplified in certain regions according to land-sea temperature contrasts. If various sources of forcing for the annual cycle could be distinguished, then it may be easier to contextualize long-term variability such as intra-decadal oscillations in climate. The separation of short- and long-term cycles is possible through statistical time series analysis, as reported here. However, the separation of local and remote forcing in the spatial domain is more difficult.

Biasutti et al. (2003) analysed the annual cycle around the tropical Atlantic, where it is known to be large relative to interannual fluctuations of sea surface temperature (SST). They found the role of SST in the annual cycle of air temperature and precipitation to be large over the Atlantic Ocean, the Guinea coast of Africa and north-east Brazil. The role of insolation is large over the highlands of Africa and the sub-tropics of South America. The interaction between these two forcings is small in their numerical model results and impacts of the Indian Ocean monsoon were not considered.

The African continent straddles the equator (Fig. 1) and its convection is a significant source of atmospheric heat. It has an extended plateau, two large deserts, and borders two tropical oceans of markedly different character. Energy released over equatorial Africa is exported through tropical/extra-tropical interactions, causing feedback with the global circulation and regional monsoons. The annual cycle of African rainfall is particularly strong and is expected to follow the pattern of the meridional flow set-up by the Hadley

\# Current affiliation: Tanzanian Meteorological Services, Dar es Saalam.

* To whom all correspondence should be addressed.

皿+2735 902-6326; fax:+2735 902-6317;

e-mail: mjury@pan.uzulu.ac.za

Received 7 July 2004; accepted in revised form 22 September 2004.

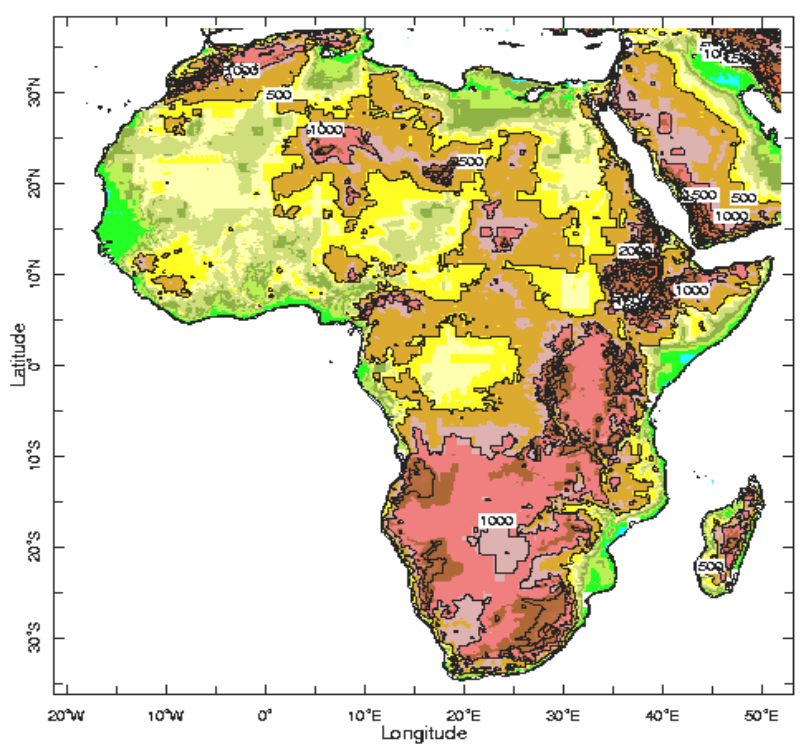

Figure 1

Topographic map of Africa distinguishing the southern highlands / northern lowlands. Many of the following PCA patterns conform to these features.

cell and its association with land-surface characteristics and the surrounding oceans.

The monsoon circulation over Africa and its adjacent oceans undergoes shifts: In austral summer a convective trough extends from the Congo to Madagascar (Mulenga, 1998; Nassor and Jury 1998), in boreal summer a trough extends west-ward along the Guinea coast. Both features link with oceanic inter-tropical convergence zones (ITCZ); Jury et al., 1994). Heat and moisture are transported by cross-equatorial flows, comprising the lower limb of the Hadley overturning circulation. The NE monsoon of the Indian Ocean and SW monsoon of the Atlantic both provide essential inflows that depend on land-sea thermal contrasts. Heating over the subtropical deserts helps trigger the African monsoon, yet 
lateral coupling with the surrounding oceans is an important feature. Easterly waves on the pole-ward flank of the ITCZ (Jury et al., 1991) and the Madden-Julian oscillation on the equator-ward flank (Chen and Tzeng, 1989) bring rainfall to many parts of Africa.

In this study the annual cycle of the African climate is described via principal component analysis of marine circulation and continental climate data sets. An N-S dipole structure is anticipated to be the first mode of annual climate variability associated with migration of the insolation maximum and associated ITCZ. What is unknown is how closely associated are continental and oceanic monsoon systems at the annual time scale. Here we contribute to the advancement of climate science by focusing on the annual cycle and its attributes, and how it relates to climate variability.

\section{Data and methods}

The annual cycle of climate in the African region is studied using evenly gridded, model-interpolated fields based on ship- and landbased data sets. Specifically we explore rainfall and temperature over sub-Saharan Africa, and the temperature and circulation over the adjacent Atlantic and Indian Oceans. The data are comprised of 31 years (1965 to 1995) of continuous monthly data ( $N=372)$. The axes of low-level wind confluence and rainfall-producing convection over Africa at seasonal optima are the focus of our attention, using climatological mean data. Here we study the spatial and temporal patterns of the African climate (30S to $10 \mathrm{~N}, 10 \mathrm{~W}$ to $45 \mathrm{E}$ ) using station data interpolated to a $2^{\circ}$ grid (from the Climate Research Unit of the University of East Anglia), the marine circulation using SST, sea level pressure (SLP), zonal(U) and meridional (V) wind over the Indian and Atlantic Oceans (40S to 20N; 70W to 100E) from ships' data interpolated to a $10^{\circ}$ grid (from the Comprehensive Ocean Atmosphere Data Set) and background climatological information from reanalysis model data at $2.5^{\circ}$ grid (from the National Centre for Environmental Prediction). Studies employing similar data and techniques have been done for the African region by a number of researchers (e.g. Rocha, 1992; Mulenga, 1998). Here, principal component analysis (PCA) is performed to extract the annual cycle from the respective field variables, following removal of linear trends in the data $\left(\sim 1^{\circ} \mathrm{C}\right.$ for temperature). We do this for each field independently, so as to later compare the strength of inter-relationships between the earth's thermal cycle and the kinematic responses. Unrotated PC fields are used to illustrate the dipole patterns established by uneven heating across the latitudes. The resulting time scores are analysed for structure and variance each month over a mean annual cycle. Cross-correlations are evaluated to determine the level of statistical association between indicators of terrestrial climate and the marine circulation. The repetitive nature of the annual cycle and resulting autocorrelation limit the degrees of freedom, such that correlations in excess of 0.35 may be considered as statistically significant at the $95 \%$ confidence limit.

\section{Results}

\section{Mean climate at seasonal optima}

The cumulus convection associated with Africa's monsoon system is concentrated along the equator-ward flanks of the subtropical deserts, where high temperatures are present as illustrated in Fig. 2. Ba and Nicholson (2001) have investigated the radiation budget that underpins this process. Bands of high rainfall extend from the western Congo into south-eastern Africa in December to March and into north-west Africa in June to September (Fig. 3). Linkages between terrestrial and marine rainfall are evident: The austral

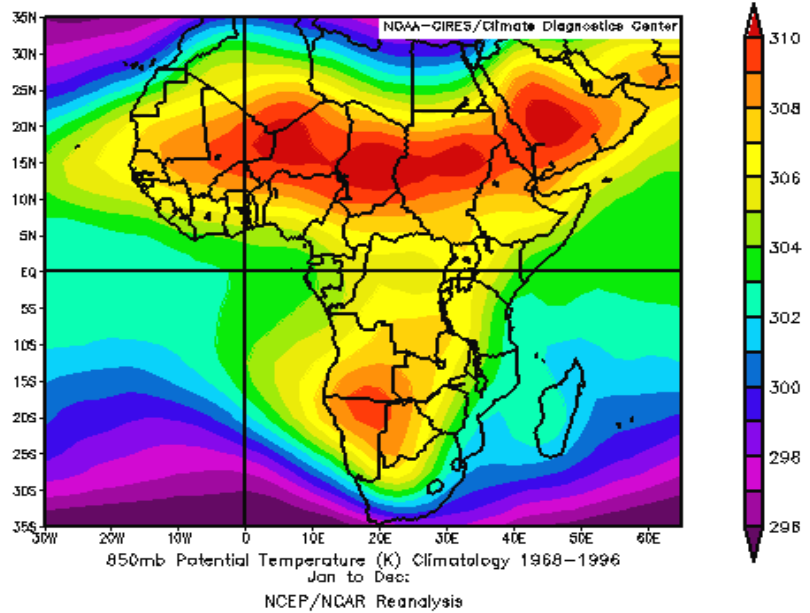

Figure 2

Mean annual potential temperature at $850 \mathrm{hPa}$ illustrating effects of insolation over the northern and southern deserts
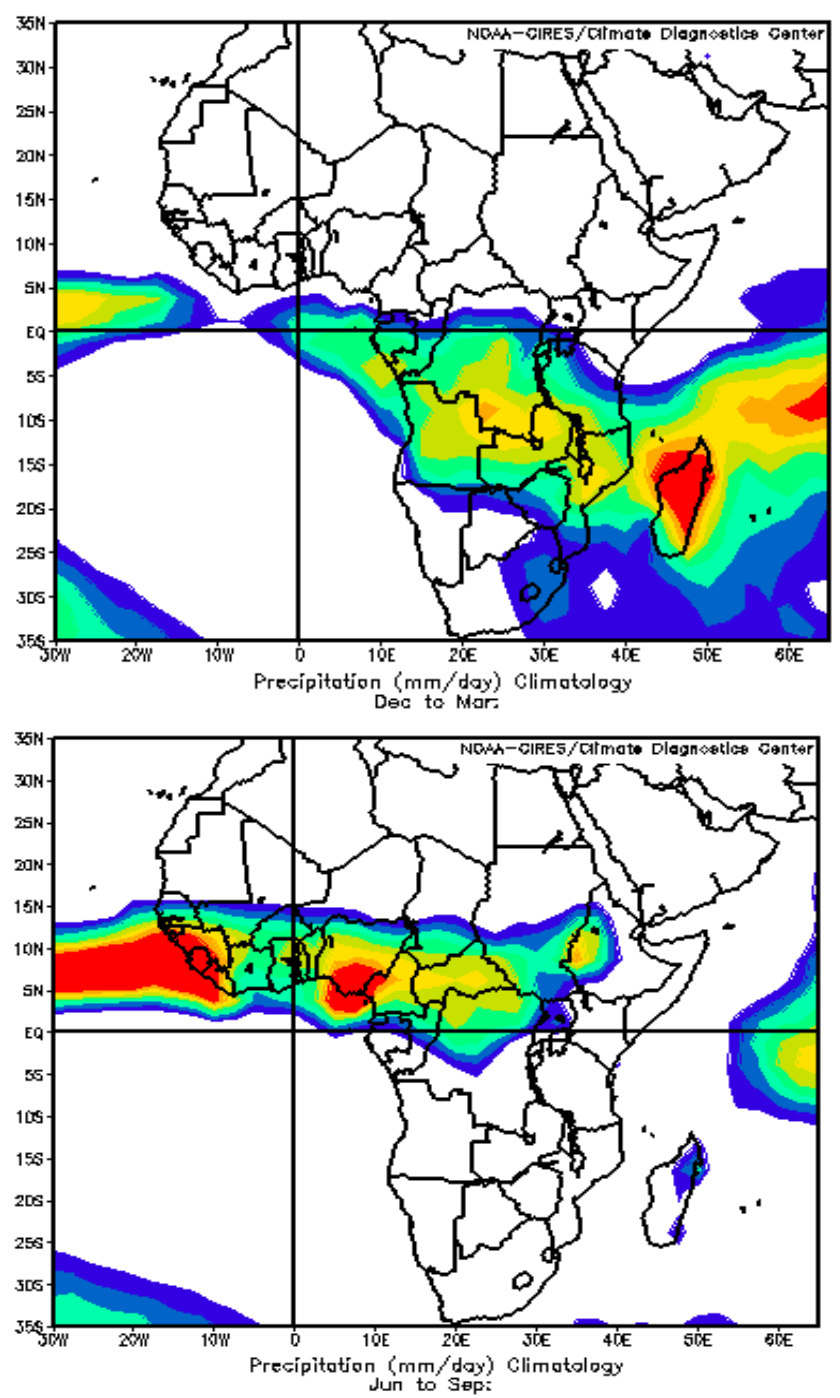

Figure 3

Seasonal mean precipitation from blended CMAP data for (top) December to March, and June to September. Colours are blue $>2$, green $>3$, yellow $>4$ and red $>5 \mathrm{~mm} /$ day. 
TABLE 1

PC modes, variance, and approximate locations for African climate

\begin{tabular}{|l|c|l|}
\hline PC mode & Variance & Structure/location \\
\hline Rain-PC1 & $47.6 \%$ & N-S dipole (10-15 lat. - Africa) \\
Rain-PC2 & 11.8 & Equatorial band (Africa) \\
Temp-PC2 & 23.2 & N-S dipole (10-15 lat. - Africa) \\
SST-PC1 & 68.9 & N-S dipole (10-25 lat. - both oceans) \\
SST-PC2 & 14.2 & Equatorial band (both oceans) \\
SLP-PC1 & 45.6 & N-S dipole (Indian) + South Atlantic \\
SLP-PC2 & 12.7 & E-W dipole (tropical Indian / north Atlantic) \\
Vwind-PC1 & 35.5 & Equatorial band (both oceans) \\
Uwind-PC1 & 33.8 & N-S dipole (10-20 lat. - both oceans) \\
\hline
\end{tabular}
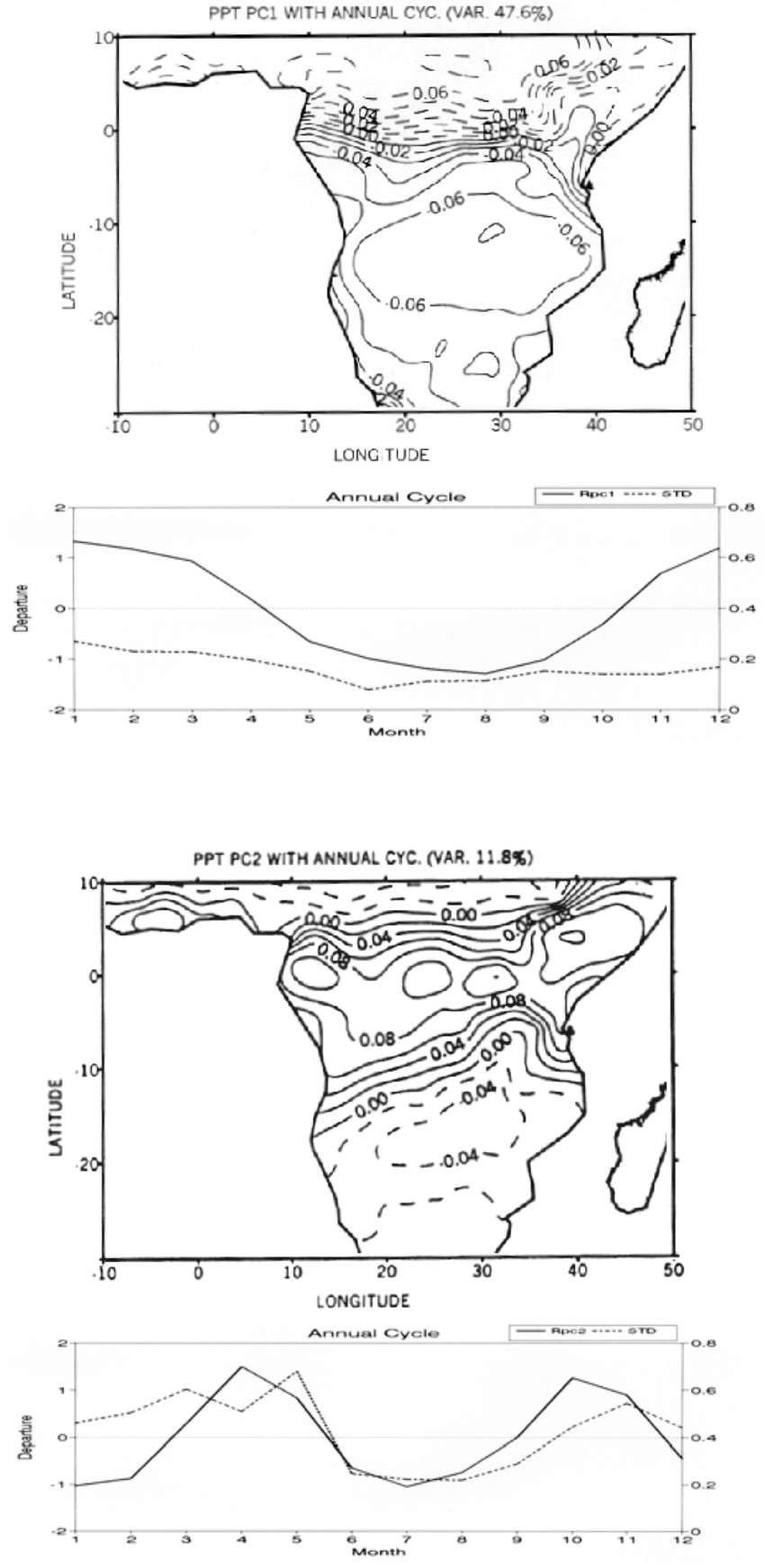

Available on website http://www.wrc.org.za summer monsoon with the Indian Ocean, and the zonally confined boreal summer monsoon with the Atlantic. Here the annual cycle of oceanic and terrestrial monsoon systems is extracted via PCA applied to unfiltered monthly data. We investigate mechanisms that modulate the annual cycle, involving both changes in monsoon intensity (i.e. N - S Hadley overturning), and shifts in time (early or late onset). These changes may be as important to mitigating the impacts of African climate as is year-to-year variability, given the amount of variance explained ( $\sim 40 \%$ annual vs. 10\% inter-annual; Mpeta, 2002).

\section{Continental rainfall and temperature}

The first two principal components (PCs) for African rainfall contribute $60 \%$ of variance (Table 1 ). Their spatial loading and mean time scores are illustrated in Figs. 4 and 5. The first mode is expressed as a dipole with opposite loadings over the Sahel (10N) and the Zambezi Valley of Southern Africa (12S). The change-over occurs at the equator. There is a meridional axis along 27E extending from the Zambezi Valley south-ward. The mean time score, based on 31 annual cycle repetitions, is sinusoidal. It dips between July and September and peaks from December and March. The southern highlands region (Kalahari-Zambezi) exhibits a more constant rainfall across the summer months, whilst the northern lowlands region (Congo-Sahel) has a seasonal peak that is more singular. Standard deviations are relatively uniform across the season, but slightly higher in months 1, 2, 3 and 9 and lower in month 6. The second rainfall mode extends across equatorial Africa with a slight WSW-ENE tilt corresponding with the highlands topography. It covers the latitudes $5 \mathrm{~N}$ to $15 \mathrm{~S}$ in the west, and $10 \mathrm{~N}$ to $9 \mathrm{~S}$ in the east. There is a minimum in loading value around 16S. PC2 contributes $12 \%$ of total variance and its temporal character is distinctly bi-modal with peaks in October and April and a minimum around July. The intervening months of May to September are drier than November to March. Highest standard deviations occur in March, May and November, and lowest in the months June to September.

The first two PCs of continental temperature contribute 78\% of variance. Unlike rainfall, the pattern for the first mode is a single area loaded north of the equator (not shown). It is the second mode that reflects an N-S dipole (Fig. 6) with opposing axes over the Kalahari-Zambezi highlands and the Congo-Sahel lowlands. The spatial pattern exposes a northern cell around $10 \mathrm{~N}$ between $15 \mathrm{E}$ and $30 \mathrm{E}$. The southern cell conforms to the topography with a maximum around 20S, 20E extending into an NE highlands axis. The mean time score exhibits a 12-month cycle, but is non-sinusoidal. There is an asymmetrical appearance with a dip in April-May and a gradual rise after July. Standard deviations are highest in months 1 to 3 and lowest in months 6, 8 and 10. October is the month when sensible heat fluxes over the Kalahari peak, prior to the onset of the summer

Figure 4 (Left, top two figures)

First PC mode of unfiltered rainfall over sub-Saharan Africa. Upper panel is spatial loading pattern, lower is mean time score. The N-S dipole pattern and annual cycle are clear.

Figure 5 (Left, bottom two figures)

Second PC mode of unfiltered rainfall over sub-Saharan Africa. Upper panel is spatial loading pattern, lower is mean time score. An equatorial pattern and 6-month oscillation are evident. 

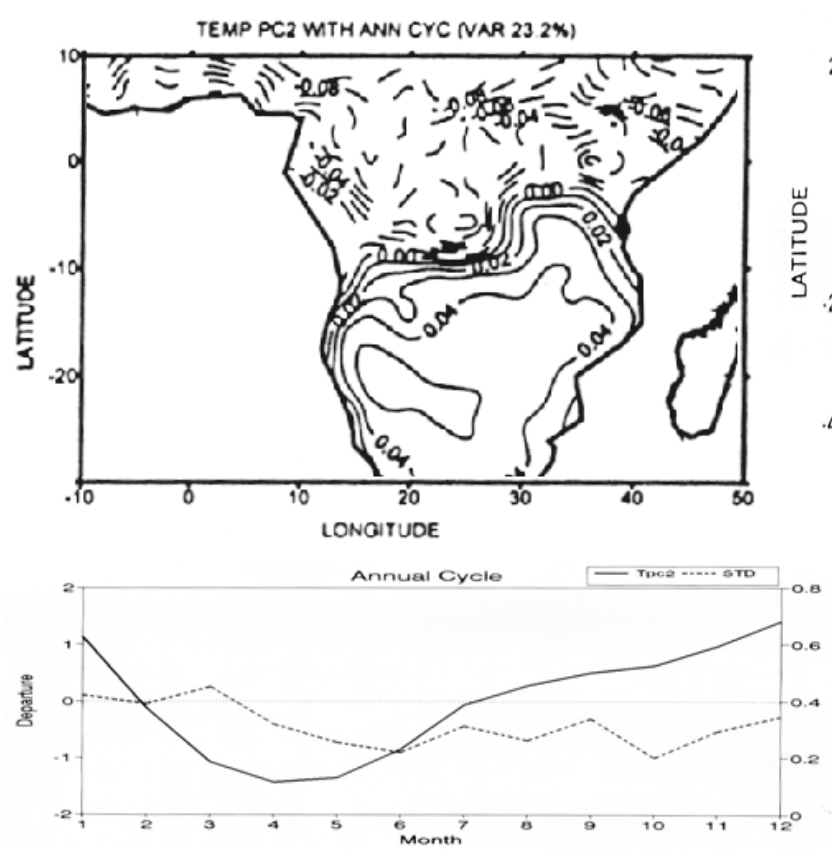

Figure 6

Second PC mode of unfiltered temperature over sub-Saharan Africa. Upper panel is spatial loading pattern, lower is mean time score. An N-S dipole pattern and 12-month cycle are evident.
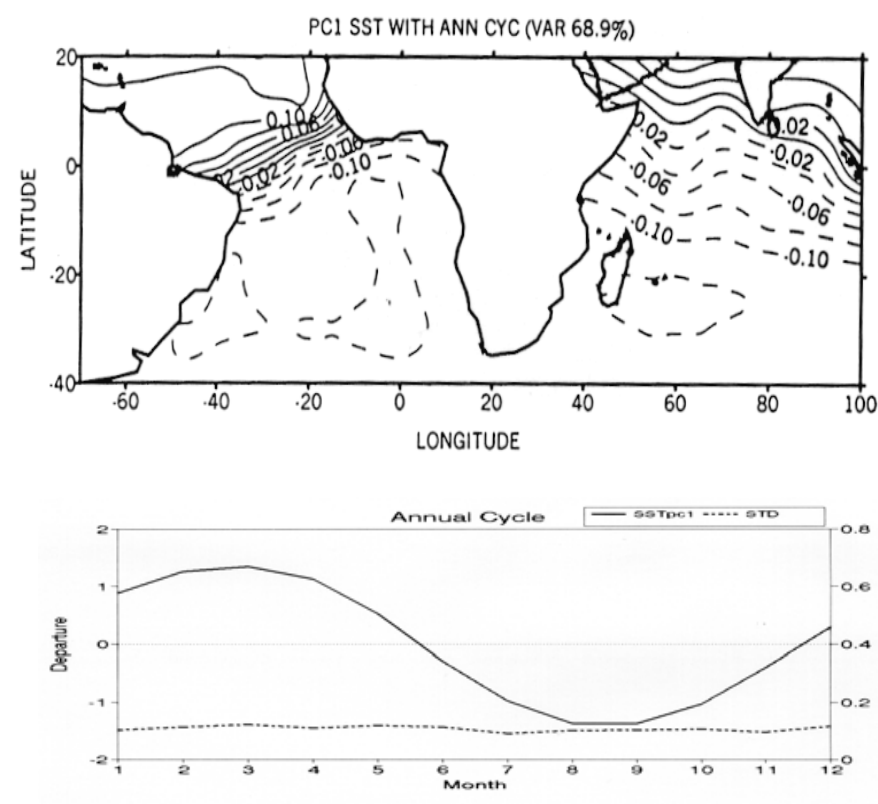

Figure 7

First $P C$ mode of unfiltered sea surface temperature over the Atlantic and Indian Oceans. Upper panel is spatial loading pattern, lower is mean time score. An N-S dipole pattern and 12-month cycle are evident.

monsoon. Like rainfall, the positive scores are flat whilst the negative scores are more peaked. We suggest that heating over the southern highlands is spread across the austral spring and summer, whilst over the northern lowlands intense heating occurs during the seasonal optimum around April.
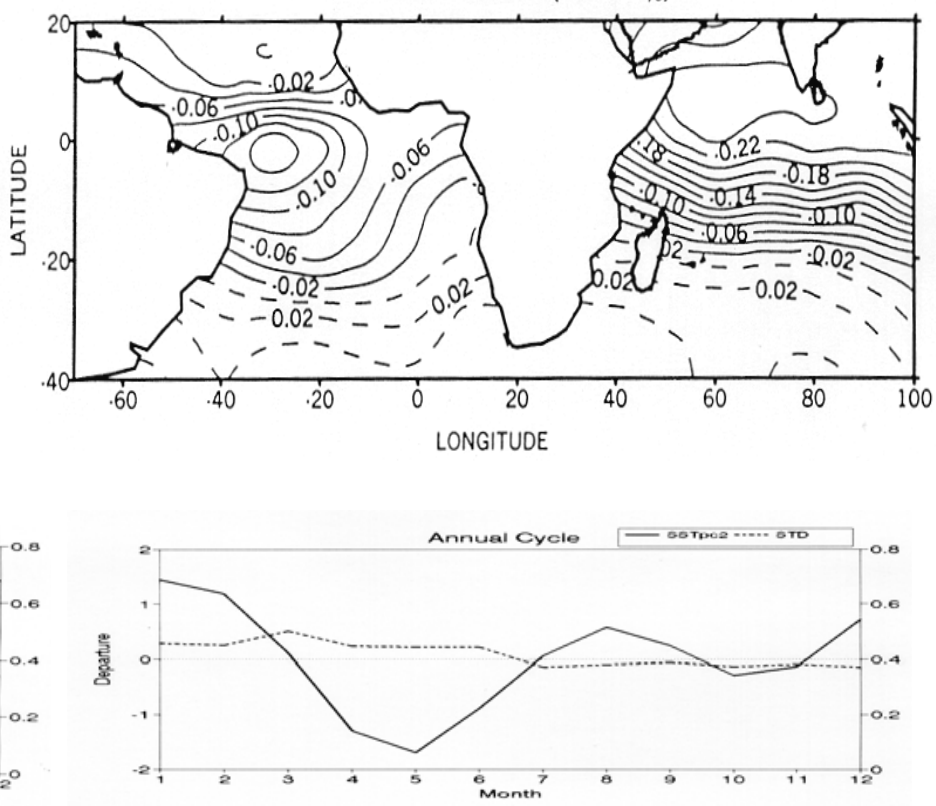

Figure 8

Second PC mode of unfiltered sea surface temperature over the Atlantic and Indian Oceans. Upper panel is spatial loading pattern, lower is mean time score. An equatorial pattern and 6month oscillation are seen.

\section{SST and pressure over the ocean}

The first two PC modes of SST over the Indian and Atlantic Oceans explain $83 \%$ of variance. The spatial pattern for the $1^{\text {st }}$ mode is an $\mathrm{N}-\mathrm{S}$ dipole that is relatively symmetrical about the equator (Fig. 7) with some skewness near Africa. The north tropical Atlantic loading values (.12) are higher than the Arabian Sea (.08) and Bay of Bengal (.06). The South Atlantic loading exhibits a meridional axis on $0 \mathrm{E}$ whilst the South Indian Ocean axis is zonal along 25S and of similar value. The mean time score, based on 31 annual cycle repetitions, is unimodal and quite sinusoidal. Peaks come two months behind the insolation maximum, e.g. high in February-March, and low in August-September of each year. Standard deviations are quite low and constant. This constancy suggests a reduced potential for 'conflict' between the annual cycle and low frequency variability. The second PC mode explains 14\% of variance (Fig. 8) and is spatially loaded in the west tropical Atlantic and north tropical Indian Ocean. The loading pattern forms a cell of value of .14 at $0 \mathrm{~S}$, $30 \mathrm{~W}$, extending over the latitudes $8 \mathrm{~N}$ to $20 \mathrm{~S}$ with a zonal structure in the north and a SW-NE tilt in the south that is consistent with SST isotherms. The Indian Ocean pattern is a stronger (0.24) zonal band centred on $5 \mathrm{~N}$, extending from $50 \mathrm{E}$ to $80 \mathrm{E}$. The positive loading region extends from $>20 \mathrm{~N}$ to $22 \mathrm{~S}$. Its mean time score exhibits two oscillations each year in response to the passage of the insolation maximum and ITCZ. Maxima occur in months 1, 2 and 8 , and minima occur in months 5 and 10 . The amplitude of the $1^{\text {st }} 6$-month cycle is greater and more variable than the $2^{\text {nd }}$. This $2^{\text {nd }}$ mode exhibits standard deviations that are three times larger than the $1^{\text {st }}$ mode.

The first two PCs of air pressure over the Indian and Atlantic Oceans contribute $58 \%$ of variability (Figs. 9 and 10). The $1^{\text {st }}$ mode contains the annual signal over the two oceans with high/low pressures in opposing hemispheres peaking in July each year. Spatial loadings are strongest over the South Atlantic (0.14) in a NW$\mathrm{SE}$ axis within the influence of the South Atlantic anticyclone. Cells 


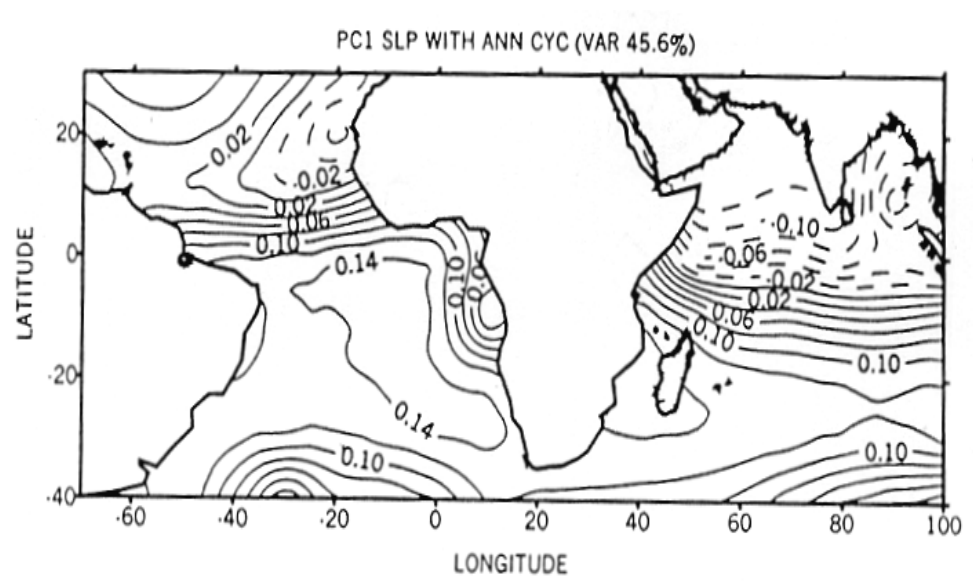

of weakly opposing sign are found off Angola and Senegal, Africa. A symmetrical pattern is found over the Indian Ocean with dipole axes at $10 \mathrm{~N}$ and $20 \mathrm{~S}$. The Arabian Sea is strongly loaded (-.12) as is the south-west Indian Ocean near Africa (+.14). The zero line lies north of the equator in the Atlantic and south of the equator in the Indian Ocean. The mean time score is sinusoidal, with a steep rise to a maximum in months 7 to 8 and a fall to a minimum in months 12,1 and 2. Standard deviations are at a maximum in months 1,2 and 8 and a minimum in months 3 and 4 . The second PC (13\%) is positively loaded over the tropical Indian Ocean and negatively loaded over the northwest Atlantic around $15 \mathrm{~N}$. This is one of the few modes that exhibit an E-W dipole. The Atlantic cell (-.22) is centred on $17 \mathrm{~N}$ near $50 \mathrm{~W}$. The Indian cell (+.16) is a zonal band with NW tilt along $5 \mathrm{~S}$, from $60 \mathrm{E}$ to $90 \mathrm{E}$. The $2^{\text {nd }}$ mode displays a

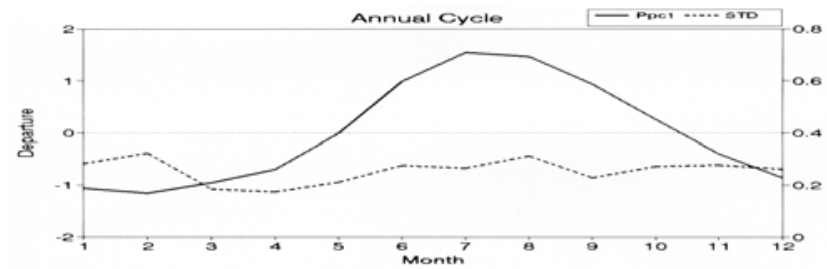

Figure 9

First PC mode of unfiltered sea level pressure over the Atlantic and Indian Oceans. Upper panel is spatial loading pattern, lower is mean time score. A 12-month cycle is evident. The pattern is an N-S dipole that is asymmetric either side of Africa.

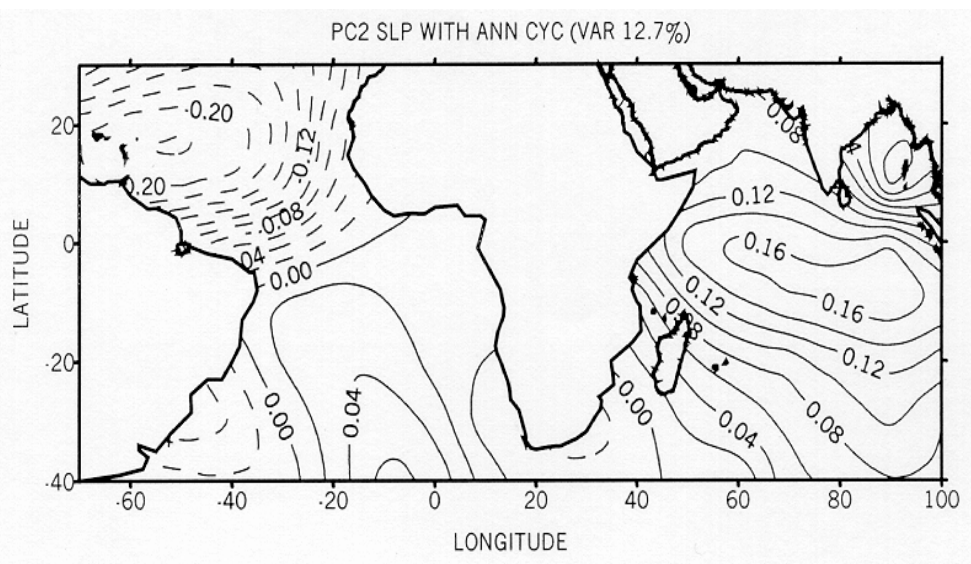
mixture of 6 and 12-month cycles. Mean time scores are flat in the early part of the year when standard deviations are the highest of any variable. A cycle occurs in the second half of the year, initially declining to a minimum around June then peaking in October.

\section{Winds over the ocean}

The first mode of cross-equatorial (V) wind explains 36\% of variance, and is dominated by the monsoon circulation over the West Indian Ocean and Gulf of Guinea (Fig. 11). Spatial loadings are greatest in the area: $10 \mathrm{~N}$ to $15 \mathrm{~S}, 40 \mathrm{E}$ to $60 \mathrm{E}$. These fan out across the southern Indian Ocean reaching 25S, the furthest extent of the monsoon. Secondary loadings are found in the southern Bay of Bengal and central Atlantic. There is an opposing sign off Senegal in the upwelling zone there. The mean time score is sinusoidal and consistent with SST. It indicates that northerly/southerly winds peak in January/July of each year. This variable, which most closely describes the monsoon circulation associated with Hadley overturning, has a 'clean' annual cycle with little spectral energy outside 12 months. Standard deviations are quite low across the year.

The first mode of zonal (U) wind explains about $34 \%$ of variance and is primarily loaded on the southern trades extending from 10S to 22S (Fig. 12). Negative loadings (westerlies) are found in the northern tropics. The dipole structure on either side of the equator in the Atlantic (+/-.6) is considerably weaker than the Indian Ocean (+/-.14). The mean time score is unimodal and

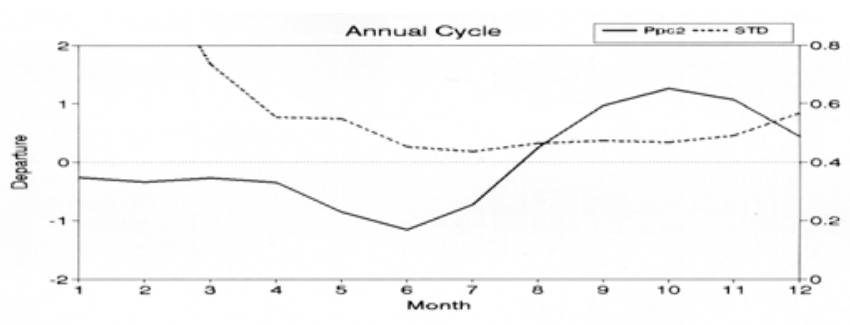

Figure 10

Second PC mode of unfiltered sea level pressure over the Atlantic and Indian Oceans. Upper panel is spatial loading pattern, lower is mean time score. Opposite loadings occur either side of Africa. Variability is highest in January-February. declines rapidly to a minimum in June to July each year, when the easterly flow increases in the latitudes $10 \mathrm{~S}$ to 20S. This is when the monsoon of the Indian Ocean reaches greatest strength. Standard deviations are low through the year, but increase slightly around month 7 .

\section{Amplitude modulation}

Variability of the annual cycle is most prominent for the equatorial modes, according to the continuous time scores (Fig. 13). For rainfall a six-month cycle is clear. Higher amplitudes occur in wavelets whereby 3 to 8 successive years exhibit consistently high or low values. For example in 1973 to 74,1978 to 79 and 1983 to 84 a peak occurs followed by declining amplitudes. The equatorial SST scores exhibit decadal modulation with a positive trend in mid 1970s and a negative trend in the late 1980s. For the E-W pressure dipole coherent amplitudes prevail in 1972 to 1978 and 1988 to 1992 . There 


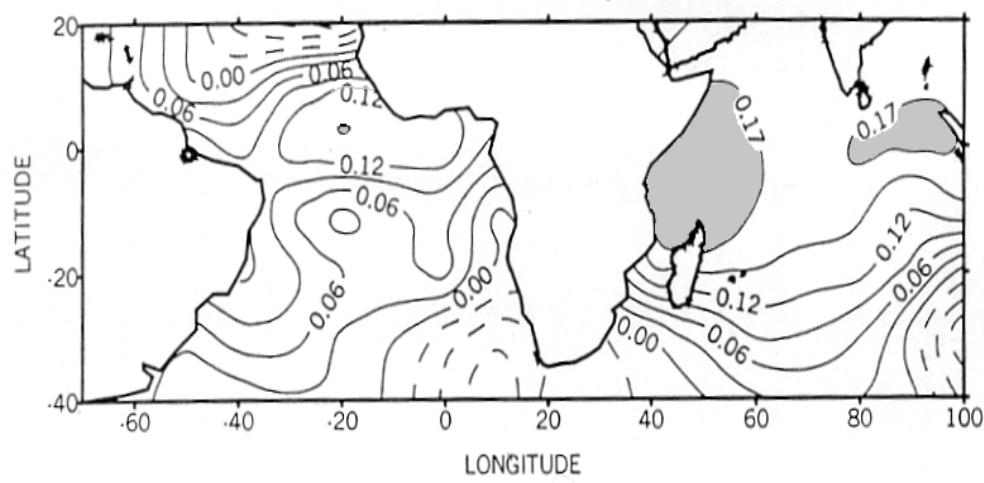

is a particular phase when annual and bi-annual cycles interact, e.g. when Atlantic pressure is rising and Indian is falling.

Relationships between the amplitude of the annual cycle and the El Nino - Southern Oscillation (ENSO) are explored using time scores for the $\mathrm{N}-\mathrm{S}$ rainfall dipole (PC1). We consider the difference between peak values for austral and boreal summer and central Pacific (Nino3) SST (Fig. 14). The cross-correlation for January SST and January minus July rainfall scores is -.49. Applying a $\pm 1 \mathrm{C}$ threshold, it is found that rainfall amplitude is $28 \%$ greater in La Nina than in $\mathrm{El}$ Nino events. The correlation is only slightly weaker (-.46) for July SST and July minus January+1 rainfall. Hence we may conclude that the African ITCZ is more strongly developed further away from the equator in La Nina years.

The influence of the $\mathrm{N}$-S circulation on the African monsoon is studied by mapping composite years when the annual cycle (based on rainfall PC1) is high minus years when it is low, for austral and boreal summer cases. Figure 15a shows an increased Hadley overturning over the Gulf of Guinea and South Atlantic in the JuneSeptember season, with respect to years with a larger annual cycle. The signal is comprised of upper northerlies / lower southerlies in the $10 \mathrm{~S}$ to $20 \mathrm{~S}$ latitude. Additionally there is a weak increase in upper southerlies over the Sahara Desert. Together this enhances upper divergence over the Sahel- Guinea area and maintains a stronger feed of warm moist monsoon flow from the Gulf of Guinea to tropical north-west Africa. Composite patterns for the December to March season are quite different due to the N-S topographic alignment of Southern Africa. Instead a southern subtropical wavetrain is found (Fig. 15b) with alternating meridional flow at 10E, 25E, 40E and 60E longitude, with respect to years with a larger annual cycle. This pattern aids the development of a monsoon trough that connects with the ITCZ over the SW Indian Ocean (Jury, 2004).

We investigate links between the annual cycle of African climate and the surrounding ocean monsoons by analysis of cross-correlations (Table 2). SST PC1 obtains high correlation with rainfall PC1 and to some degree with temperature PC2. SST PC2 is significantly correlated with all three indicators of terrestrial climate. Pressure PC1 correlates with rainfall PC1, whilst pressure PC2 correlates with temperature PC2. We surmise that higher SST and lower pressure in the northern hemisphere favour rainfall in tropical north-

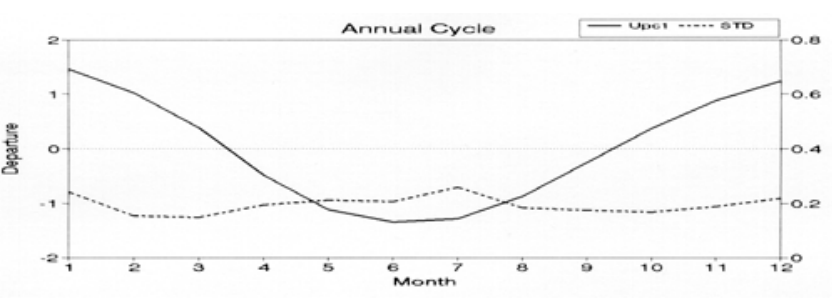

Figure 12

First PC mode of unfiltered zonal wind over the Atlantic and Indian Oceans. Upper panel is spatial loading pattern, lower is mean time score. The annual cycle of zonal winds in the Indian Ocean is pronounced. The N-S dipole implies cyclonic shear and thermocline uplift near $5 \mathrm{~S}$.
Africa, as expected. The U-wind PC correlates with rainfall PC1 and temperature PC2, whilst the monsoon V-wind PC1 correlates very highly with rainfall PC1. When the southern trades increase, rainfall increases in northern tropical Africa. Similarly, when cross-equatorial flow increases from the south, rainfall increases in the Sahel. The $96 \%$ correlation between the meridional wind over the tropical oceans and the continental rainfall dipole indicates that changes in Hadley overturning strongly modulate the amplitude of the annual cycle.

\section{Discussion}

Here an objective principal component analysis of African climate and circulation fields over the tropical Atlantic and Indian Oceans has revealed the dominant mode as a subtropical N-S dipole pattern with high amplitudes confined near the 12-month period following the pattern of solar insolation. Second mode loading patterns are 

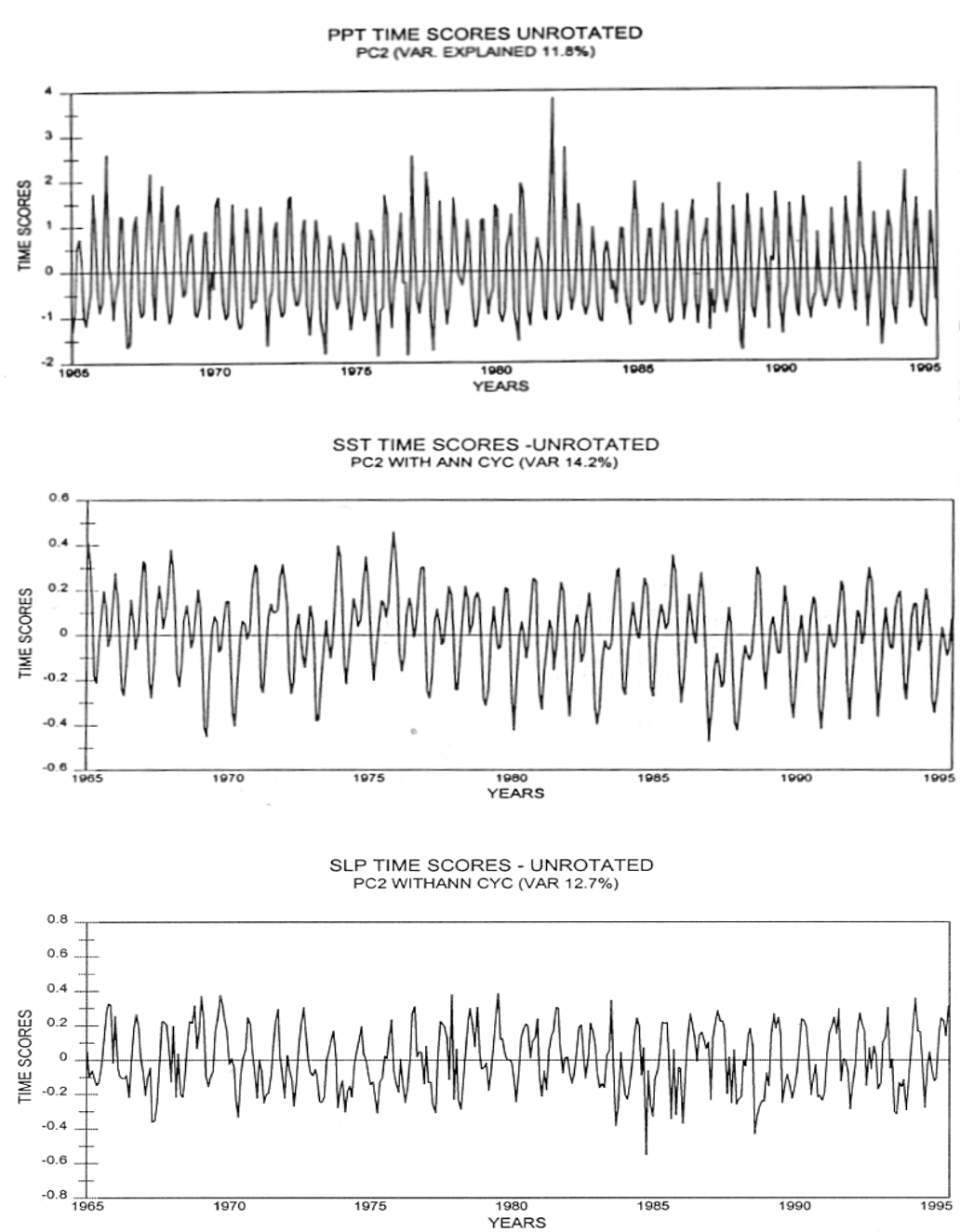

Figure 13

Continuous time scores for second mode (equatorial) PCs of rainfall (top), SST and pressure (lower) revealing low frequency modulation of the annual cycle

concentrated on the equatorial band where the sun crosses twice a year. Although inter-annual variability is often the focus of climate research, its variance is of the order of $10 \%$ compared to $\sim 40 \%$ of variance for the annual cycle. The two frequencies are intertwined such that years of high (low) annual cycle correspond with La Nina (El Nino) and increased (decreased) inter-annual fluctuations of African climate. There are spells lasting 3 to 8 years when the amplitude of the annual cycle for rainfall varies coherently (e.g. low: 1968-1973, high: 1974 to 1978, low: 1980 to 1987, high: 1988 to 1992, low: 1994+). This results from atmospheric interactions of the Hadley cell over the tropical South Atlantic, standing waves in the southern subtropical jet, and the global ENSO. Similarly, there are oceanic processes involving a zonal seesaw of the tropical thermocline initiated by Rossby waves with 1 to 10 year frequencies (Jury and Huang, 2004). We conclude that the ITCZ is most strongly developed at $10 \mathrm{~N}$ and $10 \mathrm{~S}$ during global La Nina events, whilst in El Nino events Africa's convection is more equatorial in nature. The prediction of intensity and timing of the annual cycle and its rain and temperature fields is the next step in this research, to improve the strategic management of climate-impacted resources over the African continent.

\section{Acknowledgements}

A part of this work originates from the Ph.D. thesis of the second author. The first author received support from the Water Research Commission (WRC) and the National Research Foundation of South Africa (NRF).

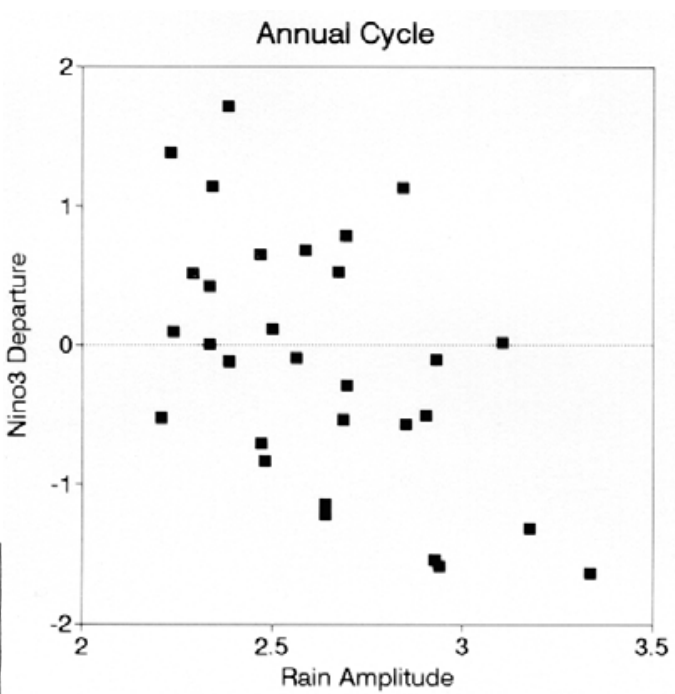

Figure 14

Scatterplot of rainfall (PC1) amplitude and Pacific Nino3 SST, demonstrating a negative correlation (-0.49), hence increased subtropical rainfall in La Nina years.
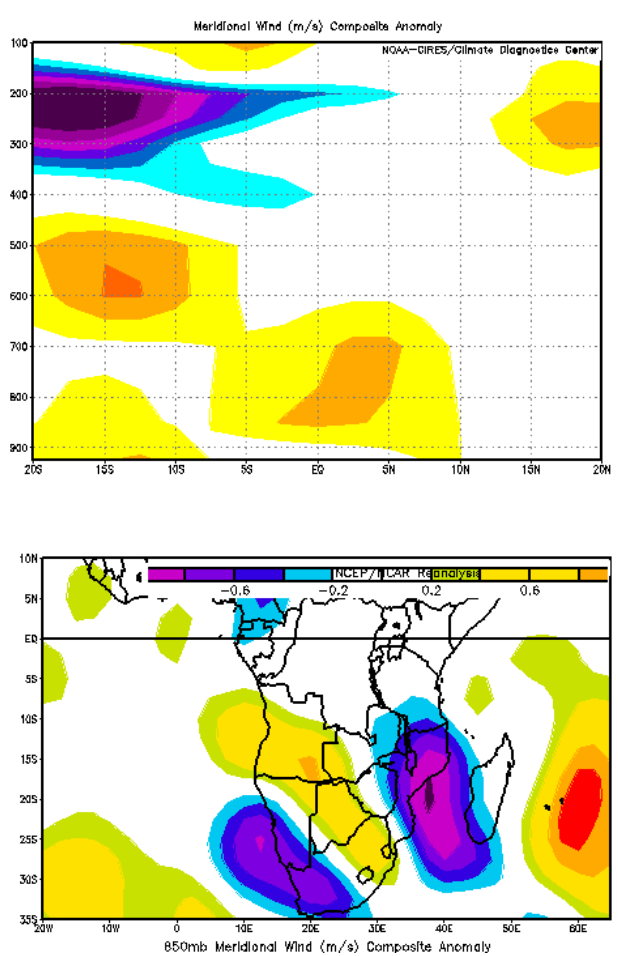

Figure 15

Composite analysis of seasons with high amplitude annual cycle minus low (based on rainfall PC1). Upper panel illustrates meridional overturning as an $\mathrm{N}$-S vertical $(y-z)$ slice for the JJAS season averaged over 0-20W. Lower panel is a composite for the DJFM season for $850 \mathrm{hPa}$ meridional winds. Blue (yellow) tones refer to southward (northward) winds. 


\section{References}

ASNANI GC (1993) Tropical Meteorology. Noble Printers, Pune, India.1202 pp.

BA MB and NICHOLSON SE (2001) Satellite derived surface radiation budget over the African continent. Part 2: Climatologies of various components. J. Clim. 14 60-76.

BIASUTTI M, BATTISTI DS and SARACHIK ES (2003) The annual cycle over the tropical Atlantic, South America and Africa. J. Clim. 15 2491-2508.

CHEN TC and TZENG R (1989) Global scale intra-seasonal and annual variation of divergent water vapour flux. Meteorol. Atmos. Phys. 44 133-151.

JURY MR (2004) Personal communication on "Fast oscillations within the annual cycle of the southern African - Indian monsoon". Environmental Science Dept, University of Zululand, RSA.

JURY MR, PATHACK B, CAMPBELL G, WANG B, LANDMAN W (1991) Transient convective waves in the tropical SW Indian Ocean. Meteorol. Atmos. Phys. 47 27-36.
JURY MR, PARKER BA and WALISER D (1994) Evolution and variability of the ITCZ in the SW Indian Ocean: 1988-1990. Theorol. Appl. Climatol. 48 187-194.

JURY MR and HUANG B (2004) The Rossby wave as a key mechanism of Indian Ocean climate variability. Deep Sea Res. (in press).

MPETA E J (2002) Mechanisms of Inter-Annual Rainfall Variability Over the Tropical Highlands of Africa. Ph.D. Thesis, University of Zululand, South Africa. 214 pp.

MULENGA HM (1998) Southern African Climatic Anomalies, Summer Rainfall and the Angola Low. Ph.D. Thesis, Oceanography Dept, Univ of Cape Town. 232 pp.

NASSOR A and JURY MR (1998) Intra-seasonal climate variability of Madagascar. Part 1: mean summer conditions. Meteorol. Atmos. Phys. 65 31-41.

ROCHA A (1992) The Influence of Global SST on Southern African Summer Climate. Ph.D. Thesis, University Melbourne, Australia. 249 pp. 